\title{
Radical Polymerization of Highly Isotactic and Syndiotactic Poly(methyl methacrylate) Macromonomers
}

\author{
Eiji Masuda, Shigeki Kishiro, Tatsuki Kitayama, \\ and Koichi HaTADA* \\ Department of Chemistry, Faculty of Engineering Science, \\ Osaka University, Toyonaka, Osaka 560, Japan
}

(Received October 12, 1990)

\begin{abstract}
Highly isotactic (iso-) and syndiotactic (syn-) poly(methyl methacrylate) (PMMA) macromonomers having styrene end group were prepared by the reaction of the corresponding PMMA living anions with $p$-vinylbenzyl bromide and their polymerizations were studied in toluene using $2,2^{\prime}$-azobisisobutyronitriie as an initiator. The rate of polymerization $\left(R_{\mathrm{p}}\right)$ of iso-PMMA macromonomer was slightly higher than that of syn-macromonomer. A similar tacticity dependence of the reactivity was also observed in the radical copolymerization of the macromonomers with styrene. Propagation rate constant $\left(k_{\mathrm{p}}\right)$ for the homopolymerization of macromonomers was estimated from $R_{\mathrm{p}}$, termination rate constant $\left(k_{\mathrm{t}}\right)$ determined by ESR spectroscopy [K. Hatada $e t$ al., Makromol. Chem., Rapid commun., 11, 101 (1990)] and initiator efficiency $(f)$ determined from end group analysis of polymacromonomer by means of NMR spectroscopy [T. Kitayama et al., Polym. Bull., 25, 205 (1991)]. Both the $k_{\mathrm{t}}$ and $k_{\mathrm{p}}$ values were much smaller than those for styrene polymerization, and the decrease of $k_{\mathrm{t}}$ of the macromonomer was much more evident than the decrease of $k_{\mathrm{p}}$. The $k_{\mathrm{p}}$ and $k_{\mathrm{t}}$ values for $i s o$-macromonomer were much larger than the corresponding values for the syn-one. The results suggest that the higher segmental mobility of iso-PMMA chain than that of syn-PMMA chain brings about the larger rate constants for propagation and termination reactions.
\end{abstract}

KEY WORDS PMMA Macromonomer / Stereoregularity / Tacticity /

Propagation / Termination / Monomer Reactivity Ratio / Initiator Efficiency /

Many papers have been published on the syntheses and applications of macromonomers. ${ }^{1-5}$ Especially, macromonomers of high purity and narrow molecular weight distribution (MWD) have been desired for the syntheses of graft or comb-like polymers which have well-defined structures. Characteristic features of the radical polymerization of macromonomers have been studied by kinetic experiments. ${ }^{6-14}$ However, little attention has been paid to the tacticity of the macromonomers. ${ }^{15-17}$

Poly(methyl methacrylate) (PMMA) is one of the typical polymers whose tacticity can be widely varied by changing the reaction conditions and whose properties in bulk and in solution depend strongly on the tacticity. ${ }^{18,19}$ Glass transition temperature $\left(T_{\mathrm{g}}\right)$ of PMMA is much lower for the iso-PMMA than for the syn-PMMA. ${ }^{19,20}$ The ${ }^{13} \mathrm{C}$ NMR spin-lattice relaxation times of the carbons in iso-PMMA are larger than those of the corresponding carbons in syn-PMMA, indicating that the iso-polymer chains have greater segmental mobility than the syn-ones. ${ }^{21}$ Therefore, control of stereoregularity of PMMA macromonomer will provide another means for controlling the properties of graft

\footnotetext{
* To whom correspondence should be addressed.
} 
and comb-like polymers.

Recently, we found isotactic ${ }^{22,23}$ and syndiotactic $^{24,25}$ living polymerizations of methyl methacrylate (MMA) which give highly stereoregular PMMAs with the same chemical structure and narrow MWD. By utilizing these living anionic polymerization systems, highly iso- and syn-PMMA macromonomers having the same chemical structure were prepared. The preliminary results of the radical homopolymerization and copolymerization of these macromonomers were reported in the previous communication. ${ }^{26} \mathrm{We}$ also briefly reported on the observation of the propagating radicals in the polymerization of syn-PMMA macromonomer with 2,2'-azobisisobutyronitrile (AIBN) in benzene, which allowed us to directly determine termination rate constant $\left(k_{\mathrm{t}}\right)$ for the macromonomer polymerization. ${ }^{27}$

In the present work the effect of tacticity of macromonomer on the kinetic data was studied in detail for the radical polymerization of the stereoregular PMMA macromonomers.

\section{EXPERIMENTAL}

\section{Materials}

iso-PMMA macromonomer was prepared through the end-capping reaction of living isotactic PMMA, which was formed with $t-\mathrm{C}_{4} \mathrm{H}_{9} \mathrm{MgBr}$ in toluene at $-78^{\circ} \mathrm{C},{ }^{22,23}$ with $p$-vinylbenzyl bromide in the presence of 1,8 diazabicyclo[5.4.0] undec-7-ene. The detailed procedure was described in the previous communication. ${ }^{26}$

syn-PMMA macromonomers were prepared through the end-capping reaction of living syndiotactic PMMA, which was formed with $t-\mathrm{C}_{4} \mathrm{H}_{9} \mathrm{Li}-\left(n-\mathrm{C}_{4} \mathrm{H}_{9}\right)_{3} \mathrm{Al}\left(1: 3 \mathrm{~mol} \mathrm{~mol}^{-1}\right)$ in toluene at $-78^{\circ} \mathrm{C},{ }^{24,25}$ in the presence of $N, N, N^{\prime}, N^{\prime}$-tetramethylethylenediamine according to the previous communication. ${ }^{26}$

$2,2^{\prime}$-Azobisisobutyronitrile $(A I B N)$ was recrystallized from ethanol and dried in vacuo.

Toluene, purified in a usual manner and stored over sodium metal, was mixed with a small amount of $n-\mathrm{C}_{4} \mathrm{H}_{9} \mathrm{Li}$ and then vacuumdistilled.

Toluene- $d_{8}$ was dried over calcium dihydride and vacuum-distilled.

\section{Polymerization Reaction}

Polymerization was carried out in a glass ampule or in an NMR sample tube under dry nitrogen. The reaction mixture was poured into a large amount of hexane to collect the polymacromonomer and the starting macrononomer. The unchanged macromonomer was removed from the reaction product by reprecipitation from toluene solution to methanol.

\section{Measurement}

${ }^{1} \mathrm{H}$ NMR spectra were measured on JEOL JNM-FX100 (100 MHz), GSX400 (400 MHz), and GX500 (500 $\mathrm{MHz})$ spectrometers.

Gel permeation chromatography (GPC) for the characterization of macromonomer was performed on a JASCO FLC-A10 chromatograph equipped with Shodex GPC columns 802.5 and A-80M using tetrahydrofuran as an eluent. The GPC-LALLS (low-angle laser light scattering) experiment for polymacromonomer was performed on a Tosoh HLC-801A chromatograph equipped with a LALLS detector, LS-8, which was operated with two Tosoh $\mathrm{GMH}_{\times 1}$ columns using chloroform as an eluent at $39^{\circ} \mathrm{C}$.

\section{RESULTS AND DISCUSSION}

\section{Effect of Tacticity of PMMA Macromonomer on the Radical Polymerization}

\section{(i) Homopolymerization}

Both the highly iso- and syn-PMMA macromonomers, prepared according to the procedures reported in the previous communication, ${ }^{26}$ have the same chemical structure from left end ( $t$-butyl group) to right end ( $p$ vinylbenzyl group) as follows: 
Table I. Characteristics of iso- and syn-PMMA macromonomers

\begin{tabular}{|c|c|c|c|c|c|c|}
\hline \multicolumn{3}{|c|}{ Tacicity $/ \%$} & \multirow{2}{*}{$M_{n}^{\mathrm{a}}$} & \multirow{2}{*}{$M_{w} / M_{n}{ }^{\mathrm{b}}$} & \multirow{2}{*}{$\begin{array}{c}\mathrm{CH}_{2}=\mathrm{CH}- \\
\text { per chain }\end{array}$} & \multirow{2}{*}{$\begin{array}{r}T_{\mathrm{g}} \\
{ }^{\circ} \mathrm{C}\end{array}$} \\
\hline $\mathrm{mm}$ & $m r$ & $r r$ & & & & \\
\hline 95 & 4 & 1 & 2900 & 1.12 & 0.96 & 21 \\
\hline 1 & 10 & 89 & 2720 & 1.18 & 0.97 & 95 \\
\hline 0 & 9 & 91 & 5380 & 1.15 & 0.96 & 105 \\
\hline
\end{tabular}

a Determined by ${ }^{1} \mathrm{H}$ NMR.

${ }^{b}$ Determined by GPC.

Highly iso-PMMA macromonomer<smiles>C=Cc1ccc(CC2OC(=O)C(C)(CC(C)(CC(C)(C)C)C(=O)OC)C2OC)cc1</smiles>

Highly syn-PMMA macromonomer<smiles></smiles>

The characteristics of macromonomers used in this work are summarized in Table I.

Polymerization of iso- or syn-PMMA macromonomer with AIBN in toluene- $d_{8}$ was carried out in an NMR sample tube at 60 and $80^{\circ} \mathrm{C}$. The spectral change for the polymerization mixture of iso-PMMA macromonomer at $80^{\circ} \mathrm{C}$ is shown in Figure 1. As the polymerization proceeded, the signal intensity of the vinyl group decreased, and the signals of methoxy and $t$-butyl group became broader. The amount of macromonomer consumed was determined from the relative intensity of vinyl methylene proton signals $(5.03-5.05 \mathrm{ppm}$ and $5.52-5.56 \mathrm{ppm})$ to $t$-butyl signal $(0.90 \mathrm{ppm})$. Figures 2 and 3 show the first order plots of monomer consumption of the iso- and synmacromonomers at 60 and $80^{\circ} \mathrm{C}$, respectively. These plots clearly indicate that the initial rate of polymerization $\left(R_{\mathrm{p}}\right)$ of the iso-PMMA macromonomer is high than that of the syn- one.

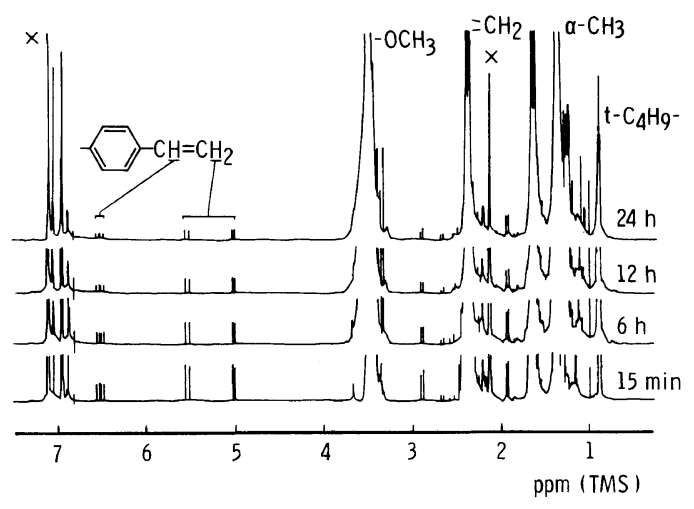

Figure 1. $400 \mathrm{MHz}{ }^{1} \mathrm{H}$ NMR spectra of polymerization mixture of iso-PMMA macromonomer $\left(M_{n}=2900\right)$ with AIBN in toluene- $d_{8}$ at $80^{\circ} \mathrm{C} . \quad[\mathrm{M}]_{0}=0.05 \mathrm{moll}^{-1}$; $[\mathrm{M}]_{\mathrm{o}} /[\mathrm{I}]_{0}=20 \mathrm{~mol} \mathrm{~mol}^{-1} . \times$, solvent signals. $30^{\circ}$ pulse, $5 \mathrm{~s} \times 32$ scans.

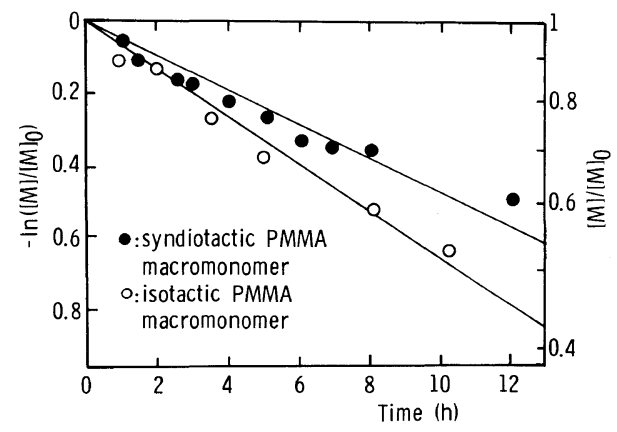

Figure 2. Effect of tacticity on the polymerization of PMMA macromonomer with AIBN in toluene- $d_{8}$ at $60^{\circ} \mathrm{C}$. $[\mathrm{M}]_{0}=0.05 \mathrm{moll}^{-1} ;[\mathrm{M}]_{0} /[\mathrm{I}]_{0}=20 \mathrm{~mol} \mathrm{~mol}^{-1} \cdot{ }^{26}$

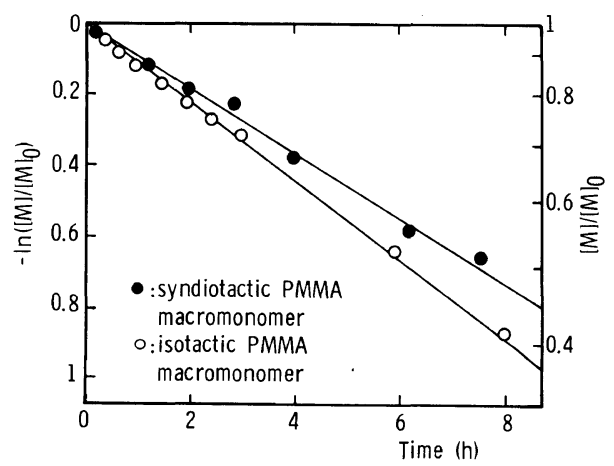

Figure 3. Effect of tacticity on the polymerization of PMMA macromonomer with AIBN in toluene- $d_{8}$ at $80^{\circ} \mathrm{C}$. $[\mathrm{M}]_{0}=0.05 \mathrm{moll}^{-1} ;[\mathrm{M}]_{0} /[\mathrm{I}]_{0}=20 \mathrm{~mol} \mathrm{~mol}^{-1}$. 
Table II. Polymerization of iso- and syn-PMMA macromonomers in toluene- $d_{8}$ for $48 \mathrm{~h}^{\mathrm{a}}$

\begin{tabular}{|c|c|c|c|c|c|c|}
\hline \multirow{2}{*}{$\begin{array}{l}\text { Macro- } \\
\text { monomer }\end{array}$} & \multirow{2}{*}{$\frac{\text { Temp }}{{ }^{\circ} \mathrm{C}}$} & \multicolumn{2}{|c|}{ Conv./\% } & \multirow{2}{*}{$M_{n}^{\mathrm{b}}$} & \multirow{2}{*}{$M_{w} / M_{n}^{\mathrm{b}}$} & \multirow{2}{*}{$\mathrm{DP}^{\mathrm{b}}$} \\
\hline & & $\mathrm{GPC}^{\mathrm{b}}$ & $\mathrm{NMR}^{\mathrm{c}}$ & & & \\
\hline \multirow{2}{*}{ iso- $^{\mathrm{d}}$} & 60 & 69 & 75 & 65300 & 1.42 & 22.5 \\
\hline & 80 & 73 & 80 & 39800 & 1.79 & 13.7 \\
\hline \multirow{2}{*}{$s y n-{ }^{\mathrm{e}}$} & 60 & 59 & 67 & 51900 & 1.38 & 19.1 \\
\hline & 80 & 64 & 68 & 33200 & 1.71 & 12.8 \\
\hline
\end{tabular}

${ }^{\mathrm{a}}[\mathrm{M}]_{0}=0.05 \mathrm{moll}^{-1},[\mathrm{I}]_{0}=0.0025 \mathrm{moll}^{-1}$.

${ }^{b}$ Determined by GPC-LALLS.

c Determined by ${ }^{1} \mathrm{H}$ NMR.

d $M_{n}=2900$.

e $M_{n}=2720$.

Table II summarizes the results of the polymerization with AIBN in toluene- $d_{8}$ at 60 and $80^{\circ} \mathrm{C}$ for $48 \mathrm{~h}$. The conversions determined by ${ }^{1} \mathrm{H}$ NMR as described above were slightly higher than those determined by GPC curves of the reaction mixtures. The results might be due to the formation of unimer of macromonomer which formed by the attack of the initiator radical but failed to propagate. The degree of polymerization (DP) was determined by GPC-LALLS, which is very useful for the determination of accurate molecular weight of branched polymer. Both DP and the conversion for iso-PMMA macromonomer were higher than the corresponding values for syn- one.

We have already found from ESR spectroscopic study ${ }^{27}$ that the termination reaction of the PMMA macromonomers is bimolecular process as in the case of ordinary radical polymerization of low molecular monomers. The result suggests that the following equations 1 and 2 for $R_{\mathrm{p}}$ and kinetic chain length $(v)$, respectively, for the ordinary radical polymerization are applicable to our present case.

$$
\begin{aligned}
R_{\mathrm{p}} & =\left(k_{\mathrm{p}} / k_{\mathrm{t}}^{0.5}\right)\left(f \cdot k_{\mathrm{d}}\right)^{0.5}[\mathrm{I}]^{0.5}[\mathrm{M}], \\
v & =\left(k_{\mathrm{p}} / k_{\mathrm{t}}^{0.5}\right)(1 / 2)\left(f \cdot k_{\mathrm{d}}\right)^{-0.5}[\mathrm{I}]^{-0.5}[\mathrm{M}]
\end{aligned}
$$

where $f, k_{\mathrm{d}}$, and $k_{\mathrm{p}}$ are initiator efficiency and the rate constants for decomposition of initiator and for propagation, respectively. [I] and $[\mathrm{M}]$ represent concentrations of initiator and monomer, respectively.

The kinetic orders with respect to macromonomer and initiator have been discussed from kinetic measurement by several research groups. The reported values for macromonomers scatter largely depending on the structure of macromonomers $\left(1.36-1.49^{6,7}\right.$ and $2.5-3.1^{8}$ ), while the values for initiators were only slightly lower than $0.5 . R_{\mathrm{p}}$ was determined at different $[\mathrm{M}]_{0}$ for the polymerizations of iso- and syn-macromonomers by ${ }^{1} \mathrm{H}$ NMR spectroscopy. For syn-macromonomer (number average molecular weight, $M n$, of 5380$), R_{\mathrm{p}}$ was $5.30 \times 10^{-7} 1 \mathrm{~mol}^{-1} \mathrm{~s}^{-1}$ at $[\mathrm{M}]_{0}=0.05 \mathrm{moll}^{-1}$, and was $2.61 \times 10^{-7}$ $1 \mathrm{~mol}^{-1} \mathrm{~s}^{-1}$ at $[\mathrm{M}]_{0}=0.025 \mathrm{moll}^{-1}$. For isomacromonomer $\left(M_{n}\right.$ of 2900$), R_{\mathrm{p}}$ was $7.40 \times$ $10^{-7} 1 \mathrm{~mol}^{-1} \mathrm{~s}^{-1}$ at $[\mathrm{M}]_{0}=0.05 \mathrm{moll}^{-1}$, and was $3.52 \times 10^{-7} 1 \mathrm{~mol}^{-1} \mathrm{~s}^{-1}$ at $[\mathrm{M}]_{0}=0.025 \mathrm{~mol}$ $1^{-1}$. The results indicate that eq 1 and 2 can actually describe the polymerization process and the kinetic rate constants can be estimated based on eq 1 .

\section{(ii) Copolymerization with Styrene}

Copolymerization of macromonomer $\left(\mathrm{M}_{1}\right)$ with low molecular weight monomer $\left(\mathrm{M}_{2}\right)$ is a facile method to examine the reactivity of macromonomers. For the analysis of copolymerization of macromonomer, Jaacks' single point experiment method ${ }^{28}$ has been widely applied. ${ }^{4,9-14}$ In this method copolymerization is carried out under the condition, $\left[\mathrm{M}_{1}\right] \ll\left[\mathrm{M}_{2}\right]$, and one of the reactivity ratios can be determined as follows:

$$
r_{2}=\frac{\log \left(\left[\mathrm{M}_{2}\right]_{\mathrm{t}} /\left[\mathrm{M}_{2}\right]_{0}\right)}{\log \left(\left[\mathrm{M}_{1}\right]_{\mathrm{t}} /\left[\mathrm{M}_{1}\right]_{0}\right)} \quad\left(\left[\mathrm{M}_{1}\right] \ll\left[\mathrm{M}_{2}\right]\right) \text {. }
$$

Then, the reactivity of $\mathbf{M}_{1}$ (macromonomer) can be estimated by $1 / r_{2}=k_{21} / k_{22}$, which represents the relative addition rate of $M_{1}$ and $\mathbf{M}_{2}$ to $\mathbf{M}_{2}$ radical. The reason why the Jaacks's 


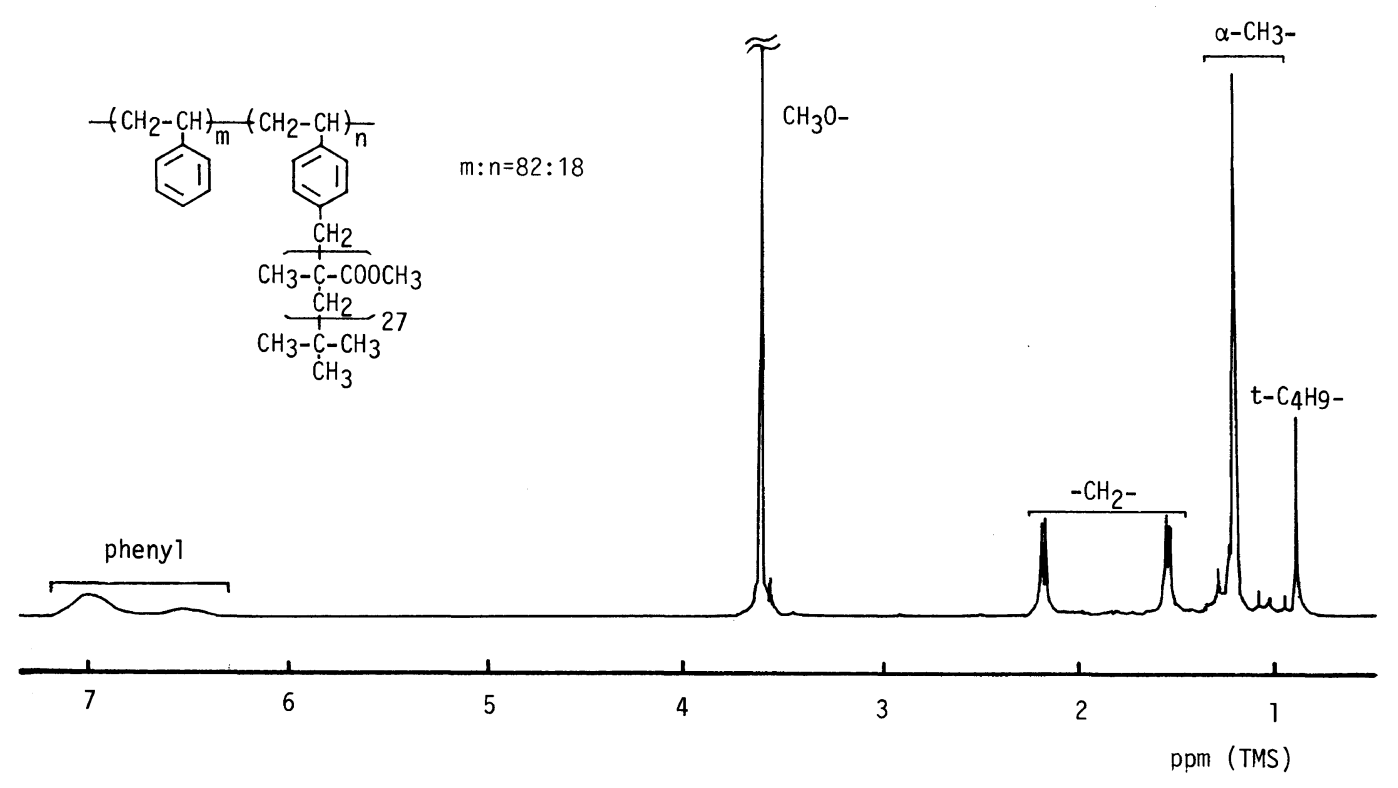

Figure 4. $500 \mathrm{MHz}{ }^{1} \mathrm{H}$ NMR spectrum of poly[styrene-co-(iso-PMMA macromonomer)] observed in $\mathrm{CDCl}_{3}$ at $55^{\circ} \mathrm{C}$.

method has been widely used instead of standard copolymerization procedure, which gives both $r_{1}$ and $r_{2}$, is that the analysis of the molar copolymer composition is very difficult for the copolymers formed under the conditions, $\left[\mathrm{M}_{1}\right] \geqq\left[\mathrm{M}_{2}\right]$, because of the large difference between molecular weights of macromonomer and low molecular weight comonomer.

The stereoregular PMMA macromonomers used in this work have one $t$-butyl group per molecule at the left end of the chain, the ${ }^{1} \mathrm{H}$ NMR signal of which is observed separately from those of the monomeric units. For copolymers with styrene, from the intensity measurements of the ${ }^{1} \mathrm{H}$ NMR signals due to the $t$-butyl group in the macromonomer units and the phenyl groups of both monomer units allow the molar fraction in the copolymer to be accurately and easily determined over a wide range of copolymer composition. Therefore, both $r_{1}$ and $r_{2}$ for the copolymerization of these macromonomers with styrene could be determined based on the Mayo-Lewis' ordinary copolymerization theory. The data should give us more profound knowledge on the copolymerization of macromonomer.

The copolymerization of iso- or syn-PMMA macromonomer $\left(\mathrm{M}_{1}\right)$ with styrene $\left(\mathrm{M}_{2}\right)$ was carried out in toluene at $60^{\circ} \mathrm{C}$ with AIBN. The reactions were terminated before the conversions of macromonomer and styrene reached $10 \%$. Both the starting macromonomers were soluble in methanol and could be easily removed from the reaction mixtures by reprecipitation from toluene solution into methanol. Figure 4 shows ${ }^{1} \mathrm{H}$ NMR spectrum of poly(iso-PMMA macromonomer-co-styrene) obtained at the initial monomer ratio $\left[\mathrm{M}_{1}\right]_{0} /$ $\left[\mathrm{M}_{2}\right]_{0}$ of $21 / 79 \mathrm{~mol} \mathrm{~mol}^{-1}$. The broad peaks observed at $6.30-7.15 \mathrm{ppm}$ were attributed to the phenyl groups of styrene and macromonomer units. The peak at $0.87 \mathrm{ppm}$ was due to $t$-butyl group of the macromonomer unit. Molar ratio of the macronomer unit to styrene unit in this copolymer was determined as $18: 82$ from the signal intensity ratio of $t$-butyl group to the phenyl groups $(1: 2.98)$.

Copolymer composition curves are shown in Figure 5. Each curve is not much far from the 


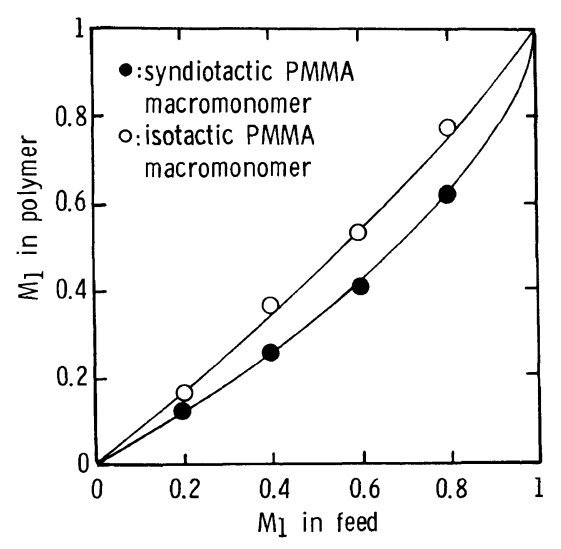

Figure 5. Copolymer composition curves for radical copolymerization of PMMA macromonomer $\left(\mathbf{M}_{1}\right)$ with styrene $\left(\mathrm{M}_{2}\right)$ by AIBN in toluene at $60^{\circ} \mathrm{C}$. $\left[\mathrm{M}_{1}\right]_{0}=0.07$ $\mathrm{moll}^{-1} ;\left[\mathrm{M}_{1}+\mathrm{M}_{2}\right]_{0} /[\mathrm{I}]_{0}=100 \mathrm{~mol} \mathrm{~mol}^{-1} \cdot{ }^{26}$

azeotrope line, indicating that the difference between the apparent reactivities of each macromonomer and styrene in the copolymerization is rather small. Table III summarizes the values of $r_{1}$ and $r_{2}$ together with those of $1 / r_{2}$. The values of $r_{1}$ and $r_{2}$ for both copolymerizations mean $k_{11}<k_{12}$ and $k_{21}<$ $k_{22}$, indicating that styrene has higher reactivity than the macromonomers toward both the macromonomer radical $\left(\mathbf{M}_{1} \cdot\right)$ and styrene radical $\left(\mathrm{M}_{2} \cdot\right)$. Then the macromonomer uints in the copolymers tend to be isolated in styrene unit sequences. Since the values of $1 / r_{2}$ $\left(=k_{21} / k_{22}\right)$ correspond to the relative reactivity of the macromonomers to styrene toward styrene radical, the larger value of $1 / r_{2}$ for the iso-PMMA macromonomer than that for the syn- one indicates the higher reactivity of iso-macromonomer; $k_{21}$ for the iso-macromonomer is 1.26 times as large as $k_{21}$ for the syn-macromonomer. In the above discussion, only the reactivity in the propagation process should be concerned, and thus the higher mobility of iso-PMMA chain ${ }^{21}$ than that of syn-PMMA chain may be related to the higher reactivity of the iso-macromonomer.

Comparison of $r_{1}$ values for iso- and synmacromonomers may not lead to simple
Table III. Reactivity ratio in the radical copolymerization of PMMA macromonomer $\left(\mathrm{M}_{1}\right)$ and styrene $\left(\mathrm{M}_{2}\right)$

\begin{tabular}{lccc}
\hline \multicolumn{1}{c}{$\mathrm{M}_{1}$} & $r_{1}{ }^{\mathrm{a}}$ & $r_{2}{ }^{\mathrm{a}}$ & $1 / r_{2}=k_{21} / k_{22}$ \\
\hline $\begin{array}{l}\text { Iso-PMMA } \\
\text { Macromonomer }\end{array}$ & 0.79 & 1.29 & 0.775 \\
& & & \\
syn-PMMA & 0.40 & 1.62 & 0.617 \\
Macromonomer & & & \\
\hline a Cited from ref 26. & & \\
b $M_{n}=2900$. \\
c $M_{n}=2720$.
\end{tabular}

conclusion on the reactivities of the macromonomer radicals because any rate constants included in $r_{1}$ does not represent the common addition steps to both copolymerizations. However, if one assumes that the effect of tacticity of the macromonomer on the rate constants for cross propagations, $k_{12}$ and $k_{21}$, are the same, that is,

$$
\frac{\left(k_{12}\right)_{\text {iso }}}{\left(k_{12}\right)_{s y n}}=\frac{\left(k_{21}\right)_{\text {iso }}}{\left(k_{21}\right)_{s y n}}
$$

the ratio $\left(r_{1} / r_{2}\right)_{i s o} /\left(r_{1} / r_{2}\right)_{s y n}$ is described as follows:

$$
\begin{aligned}
\frac{\left(r_{1} / r_{2}\right)_{\text {iso }}}{\left(r_{1} / r_{2}\right)_{\text {syn }}} & =\frac{\left(k_{11} \cdot k_{21} / k_{12} \cdot k_{22}\right)_{\text {iso }}}{\left(k_{11} \cdot k_{21} / k_{12} \cdot k_{22}\right)_{\text {syn }}} \\
& =\frac{\left(k_{11}\right)_{\text {iso }}}{\left(k_{11}\right)_{\text {syn }}} \\
& =2.5
\end{aligned}
$$

Then the rate constant of homopropagation of iso-macromonomer is estimated to be 2.5 times as large as that of syn-macromonomer. The results mean that the effect of tacticity of PMMA macromonomer is more evidently observed in the homopropagation (the addition process of macromonomer to macromonomer radical) than in cross propagation (the addition to styrene radical). This may be due to the fact that in the homopropagation process both the PMMA chain in the propagating chain end and 


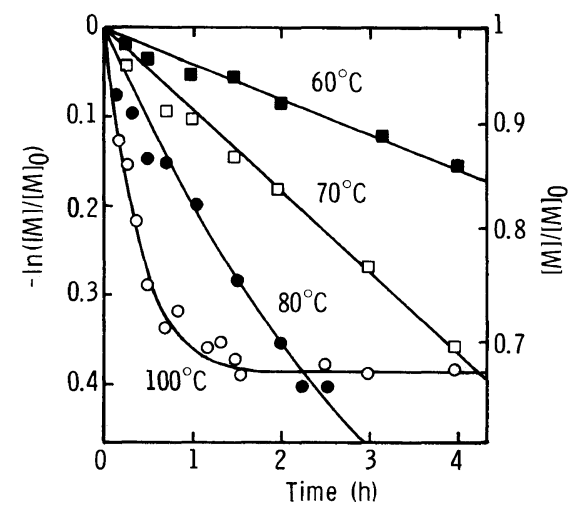

Figure 6. Effect of temperature on the polymerization of syn-PMMA macromonomer $\left(M_{n}=5380\right)$ with AIBN in toluene- $d_{8} .[\mathrm{M}]_{0}=0.05 \mathrm{moll}^{-1} ;[\mathrm{M}]_{0} /[\mathrm{I}]_{0}=20 \mathrm{~mol}$ $\mathrm{mol}^{-1}$.

that in the incoming monomer mutually interact to affect the reaction process.

\section{Effect of Temperature on the Polymerization of PMMA Macromonomer}

Figure 6 shows the first order plots of monomer consumption in the polymerization of syn-PMMA macromonomer $\left(M_{n}=5380\right)$ in toluene- $d_{8}$ with AIBN at various temperatures. The $R_{\mathrm{p}}$ 's were determined from the slope of the plots at the time of zero, and the values are shown in Table IV. Half-life times of AIBN were calculated using the literature data ${ }^{29}$ and also shown in Table IV. The deviation of the plots from the linearity at 80 and $100^{\circ} \mathrm{C}$ was explained by fast loss of AIBN at these temperatures. The Arrhenius plot of the $R_{\mathrm{p}}$ values gave a linear relationship as shown in Figure 7 and the activation energy for the overall process of polymerization $\left(E_{\text {overall }}\right)$ was determined to be $68 \mathrm{~kJ} \mathrm{~mol}^{-1}$. $E_{\text {overall }}$ is expressed as follows;

$$
E_{\text {overall }}=E_{\mathrm{p}}-E_{\mathrm{t}} / 2+E_{\mathrm{d}} / 2,
$$

where $E_{\mathrm{p}}, E_{\mathrm{t}}$, and $E_{\mathrm{d}}$ represent the activation energies for propagation, termination, and decomposition of the initiator, respectively. The value of $E_{\mathrm{t}}$ for this macromonomer was determined to be $66 \mathrm{~kJ} \mathrm{~mol}^{-1}$ by ESR spectros-
Table IV. Initial rate of polymérization $\left(R_{\mathrm{p}}\right)$ for syn-PMMA macromonomer with AIBN in toluene- $d_{8}$ at various temperatures ${ }^{\mathrm{a}}$

\begin{tabular}{|c|c|c|c|}
\hline Temp & $R_{\mathrm{p}} \times 10^{6}$ & & Half-life of AIBN ${ }^{b}$ \\
\hline${ }^{\circ} \mathrm{C}$ & $1 \mathrm{~mol}^{-1} \mathrm{~s}^{-1}$ & & $\mathrm{~h}$ \\
\hline 60 & 0.530 & 14.5 & 19.8 \\
\hline 70 & 1.06 & 13.8 & 5.11 \\
\hline 80 & 1.96 & 13.1 & 1.42 \\
\hline 100 & 7.21 & 11.8 & 0.14 \\
\hline
\end{tabular}

a Macromonomer: $M_{n}=5380,[\mathrm{M}]_{0}=0.05 \mathrm{moll}^{-1}$, $[\mathrm{M}]_{0} /[\mathrm{I}]_{0}=20 \mathrm{~mol} \mathrm{~mol}^{-1}$.

b Calculated by the equation of $\ln 2 /\left[1.58 \times 10^{15}\right.$ $\left.\exp \left(-128.9 \mathrm{~kJ} \mathrm{RT}^{-1}\right)\right]$ according to the ref 29 .

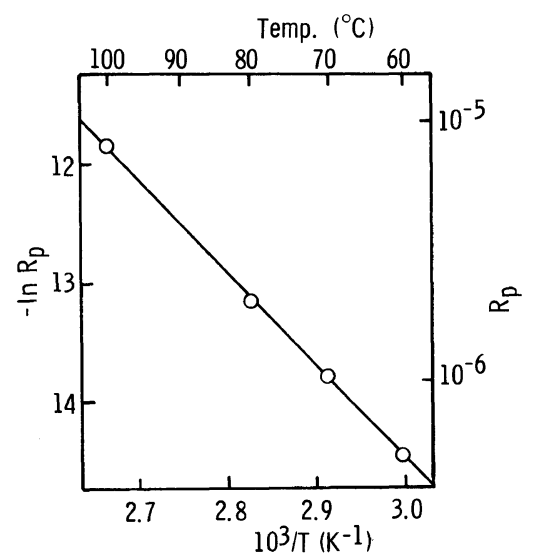

Figure 7. Arrhenius plot of $R_{\mathrm{p}}$ in the polymerization of syn-PMMA macromonomer $\left(M_{n}=5380\right)$ with AIBN in toluene- $d_{8} .[\mathrm{M}]_{0}=0.05 \mathrm{moll}^{-1} ;[\mathrm{M}]_{0} /[\mathrm{I}]_{0}=20 \mathrm{~mol}$ $\mathrm{mol}^{-1}$.

copy, ${ }^{27}$ which is much larger than that for styrene polymerization $\left(10 \mathrm{~kJ} \mathrm{~mol}^{-1}\right),{ }^{30}$ indicating that the termination reaction in the polymerization of macromonomer was highly restricted. From the $E_{\mathrm{t}}$ and $E_{\mathrm{d}}$ for AIBN $\left(128.9 \mathrm{~kJ} \mathrm{~mol}^{-1}\right),{ }^{29} E_{\mathrm{p}}$ of $s y n$-PMMA macromonomer $\left(M_{n}=5380\right)$ was determined as $36 \mathrm{~kJ} \mathrm{~mol}^{-1}$, which is slightly larger than that for styrene polymerization $\left(33 \mathrm{~kJ} \mathrm{~mol}^{-1}\right){ }^{30}$ The result indicates that propagation reaction of macromonomer is also restricted as compared with that of styrene, although the extent of the restriction in propagation reaction 
Table V. Comparison of the DP of poly(syn-PMMA macromonomer) prepared with AIBN in toluene- $d_{8}{ }^{a}$ with the DP calculated for the polystyrene prepared under the same conditions ${ }^{b}$

\begin{tabular}{|c|c|c|c|c|c|}
\hline \multirow{2}{*}{ Temp } & \multirow{2}{*}{ Macromonomer } & \multicolumn{3}{|c|}{ Styrene } & \multirow{2}{*}{$\frac{\text { AIBN }}{k_{\mathrm{d}}^{\mathrm{e}}}$} \\
\hline & & & $k_{\mathrm{p}}^{\mathrm{d}}$ & $k_{\mathrm{t}}^{\mathrm{d}}$ & \\
\hline${ }^{\circ} \mathrm{C}$ & $\mathrm{DP}^{\mathrm{c}}$ & $\mathrm{DP}^{\mathrm{b}}$ & $1 \mathrm{~mol}^{-1} \mathrm{~s}^{-1}$ & $1 \mathrm{~mol}^{-1} \mathrm{~s}^{-1}$ & $1 \mathrm{~mol}^{-1} \mathrm{~s}^{-1}$ \\
\hline 60 & 21.9 & 11.4 & 176 & $3.6 \times 10^{7}$ & $9.54 \times 10^{-6}$ \\
\hline 70 & 18.6 & 7.33 & 236 & $4.0 \times 10^{7}$ & $3.70 \times 10^{-5}$ \\
\hline 80 & 15.2 & 4.98 & 315 & $4.3 \times 10^{7}$ & $1.33 \times 10^{-4}$ \\
\hline 100 & 11.2 & 2.37 & 532 & $5.1 \times 10^{7}$ & $1.41 \times 10^{-3}$ \\
\hline
\end{tabular}

a Macromonomer: $M_{n}=5380,[\mathrm{M}]_{0}=0.05 \mathrm{moll}^{-1},[\mathrm{M}]_{0} /[\mathrm{I}]_{0}=20 \mathrm{~mol} \mathrm{~mol}^{-1}$.

${ }^{\mathrm{b}}$ Calculated from the following equation; $\mathrm{DP}=2 \cdot v=k_{\mathrm{p}} \cdot[\mathrm{M}] /\left(f \cdot k_{\mathrm{d}} \cdot k_{\mathrm{t}} \cdot[\mathrm{I}]\right)^{0.5}, f=0.7$.

c Determined by GPC-LALLS.

d Taken from ref 30 .

e Taken from ref 29.

is less remarkable than that in termination reaction.

Table V shows the DP's of the polymacromonomers and polystyrenes prepared at various temperatures. The DP's for the polystyrene formed under the same conditions as those for the macromonomer were calculated by using rate constants taken from a literature $^{30}$ on the assumption that DP is $2 \cdot v$, even though a part of polystyrene radicals terminate through disproportionation reaction. ${ }^{31}$ The DP's of polymacromonomers were higher than those of polystyrene, indicating the value of $k_{\mathrm{p}} / k_{\mathrm{t}}^{0.5}$ for the polymerization of macromonomer was higher than that for styrene polymerization ( $c f$., eq 2 ). Figure 8 shows the plot of $\log$ DP against the reciprocal of temperature. A linear relationship was obtained as in the case of radical polymerization of usual monomers.

\section{Kinetics of Radical Polymerization of Stereo-} regular PMMA Macromonomer

As mentioned previously, the mobility of PMMA chain strongly depends on its tacticity in bulk ${ }^{18-20}$ and in solution, ${ }^{18,19,21}$ and isoPMMA chain has higher mobility than synPMMA chain. The mobility of the macromonomer should affect each reaction process

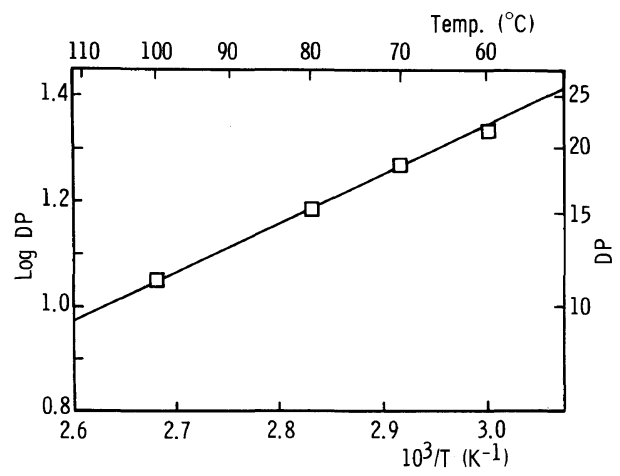

Figure 8. Plots of $\log$ DP of the poly(syn-PMMA macromonomer) against the reciprocal of polymerization temperature. The polymerizations were carried out in toluene- $d_{8}$ for $48 \mathrm{~h}$. $[\mathrm{M}]_{0}=0.05 \mathrm{moll}^{-1} ;[\mathrm{M}]_{0} /[\mathrm{I}]_{0}=$ $20 \mathrm{~mol} \mathrm{~mol}^{-1}$.

in the polymerization. Thus the difference of $R_{\mathrm{p}}$ and DP in the polymerizations of iso- and syn-macromonomers should be caused by the difference of their mobilities. However, eq 1 and 2 mean that both $R_{\mathrm{p}}$ and DP are proportional to the value of $k_{\mathrm{p}} / k_{\mathrm{t}}^{0.5}$, and thus the larger $R_{\mathrm{p}}$ and $v$ do not necessarily mean the larger values of both $k_{\mathrm{p}}$ and $k_{\mathrm{t}}$, since these constants act in opposite ways on $R_{\mathrm{p}}$ and $v$. Then, in order to clarify the effects of stereoregularity of the PMMA macromonomers on their radical polymerization, further 
Table VI. Kinetic parameters for the polymerization of PMMA macromonomers or styrene in toluene at $60^{\circ} \mathrm{C}$ with AIBN $^{\mathrm{a}}$

\begin{tabular}{|c|c|c|c|c|c|c|c|}
\hline \multicolumn{2}{|c|}{ Macromonomer } & \multirow{2}{*}{$\frac{R_{\mathrm{p}} \times 10^{6}}{\mathrm{moll}^{-1} \mathrm{~s}^{-1}}$} & \multirow{2}{*}{$f^{b}$} & \multirow{2}{*}{$\frac{k_{\mathrm{p}}}{1 \mathrm{~mol}^{-1} \mathrm{~s}^{-1}}$} & \multirow{2}{*}{$\frac{k_{\mathrm{t}}^{\mathrm{c}}}{1 \mathrm{~mol}^{-1} \mathrm{~s}^{-1}}$} & \multirow{2}{*}{$v^{\mathrm{d}}$} & \multirow{2}{*}{$\mathrm{DP}^{\mathrm{e}}$} \\
\hline Tacticity & $M_{n}$ & & & & & & \\
\hline iso- & 2900 & 0.74 & 0.28 & 50 & $70000^{f}$ & 58 & 22.5 \\
\hline syn- & 2720 & 0.66 & 0.22 & 4.7 & $670^{f}$ & 63 & 19.1 \\
\hline syn- & 5380 & 0.53 & 0.18 & 3.9 & 590 & 61 & 21.9 \\
\hline \multicolumn{2}{|c|}{ Styrene monomer } & $0.19^{8}$ & $0.7^{\mathrm{h}}$ & $176^{i}$ & $3.6 \times 10^{7 \mathrm{i}}$ & 5.7 & - \\
\hline
\end{tabular}

${ }^{\mathrm{a}}[\mathrm{M}]_{0}=0.05 \mathrm{mol1}^{-1},[\mathrm{M}]_{0} /[\mathrm{I}]_{0}=20 \mathrm{~mol} \mathrm{~mol}^{-1}$.

${ }^{b}$ Initiator efficiency taken from the ref 36.

c Taken from the ref 27 and 33.

${ }^{d}$ Kinetic chain length estimated from eq 2.

e Determined by GPC-LALLS for the polymacromonomer formed in the polymerization for $48 \mathrm{~h}$.

${ }^{f}$ Estimated by extrapolation of the data obtained at lower temperatures. ${ }^{33}$

8 Calculated from the literature data and eq 1.

h Taken from the ref 34.

i Taken from the ref 30 .

information such as the rate constants for the elementary processes is required. For this purpose, we determined $k_{\mathrm{t}}$ values by ESR spectroscopy ${ }^{33,34}$ as well as initiator efficiencies ( $f$ 's) by ${ }^{2} \mathrm{H}$ NMR spectroscopy, ${ }^{36}$ and estimated $k_{\mathrm{p}}$ values for the radical polymerization of macromonomers as described below.

ESR spectroscopy is the most promising way for the study on the nature of propagating radicals ${ }^{32}$ and was recently applied to the radical polymerization of macromonomer. ${ }^{27,33,34}$ We reported that the propagating radicals in the polymerization of syn-PMMA macromonomer $\left(M_{n}=5380\right)$ could be observed by using ESR spectroscopy, and $k_{\mathrm{t}}$ values in the temperature range from 30 to $60^{\circ} \mathrm{C}$ were determined from the decay of the ESR signal. ${ }^{27}$ Lately, ESR signals of propagating radicals of iso-PMMA macromonomer $\left(M_{n}=2900\right)$ could also be observed successfully at and below $30^{\circ} \mathrm{C}$, and the $k_{\mathrm{t}}$ values were determined in the temperature range from 10 to $30^{\circ} \mathrm{C}^{33}$ Since an Arrhenius plot of the $k_{\mathrm{t}}$ gave a linear correlation, $k_{\mathrm{t}}$ value at $60^{\circ} \mathrm{C}$ was estimated by extrapolation of the $k_{\mathrm{t}}$ 's at lower temperatures. The values of $k_{\mathrm{t}}$ for synmacromonomer with $M_{n}$ of 2720 could be determined similarly in the temperature range from 20 to $50^{\circ} \mathrm{C},{ }^{33}$ and the $k_{\mathrm{t}}$ at $60^{\circ} \mathrm{C}$ was estimated by extrapolation as in the case of iso-macromonomer. The values are summarized in Table VI.

The PMMA macromonomers were polymerized in toluene at $60^{\circ} \mathrm{C}$ using AIBN- $d_{12}$ and the initiator fragments in the resultant polymacromonomers were analyzed by ${ }^{2} \mathrm{H}$ NMR spectroscopy to determine the $f$ values. ${ }^{35,36}$ The $f$ values thus obtained are listed in Table VI, all of which are lower than that for bulk or solution polymerization of styrene $(0.5-0.7) .{ }^{37}$ The results suggest that a large amount of the primary radicals fail to initiate the polymerization of macromonomer as compared with the case of the polymerization of ordinary monomer owing to high viscosity of the reaction media from the initial stage of polymerization.

From eq 1 and the value of $k_{\mathrm{d}}$ available from the literature, ${ }^{29}$ the $k_{\mathrm{p}}$ 's for the polymerization of PMMA macromonomers were estimated from the values of $R_{\mathrm{p}}, f, k_{\mathrm{t}}$, and $k_{\mathrm{d}}$. The results are summarized in Table VI.

Although both $k_{\mathrm{p}}$ 's and $k_{t}$ 's for the PMMA macromonomers are smaller than the corresponding values of styrene, the $R_{\mathrm{p}}$ for the macromonomers were larger than that for styrene 
(Table VI). This means that, even though $k_{\mathrm{p}}$ 's for the macromonomers are smaller than that for styrene, extremely smaller $k_{\mathrm{t}}$ values for the macromonomers than that for styrene bring about the larger $R_{\mathrm{p}}$ 's for the macromonomers than styrene.

The $R_{\mathrm{p}}$ for iso-PMMA macromonomer is higher than that for syn-PMMA macromonomer. The $k_{\mathrm{t}}$ value for the iso-macromonomer was about 100 times as large as that for the syn-macromonomer of a similar $M_{n}$. The $k_{\mathrm{p}}$ for the iso-macromonomer is about 10 times as large as that for the syn-macromonomer. Effect of tacticity of the macromonomer is much greater on the termination reaction than on the propagation reaction. This is probably because the termination process involves the reaction between two propagating radical centers both of which should be surrounded by many PMMA segments while the propagation process involves the reaction of one propagating radical with a macromonomer which consists of a single PMMA chain. The difference between $R_{\mathrm{p}}$ 's for iso- and syn-macromonomers is not so remarkable since $R_{\mathrm{p}}$ is proportional to $k_{\mathrm{p}} / k_{\mathrm{t}}^{0.5}$ and thus the increases of $k_{\mathrm{p}}$ and $k_{\mathrm{t}}$ affect $R_{\mathrm{p}}$ in opposite ways. The difference in $R_{\mathrm{p}}$ is mostly accounted for the difference in $f$ values as seen in Table $\mathrm{V}$, that is, $\left(f_{\text {iso }} / f_{\text {syn }}\right)^{0.5}=1.12$. However, the larger $k_{\mathrm{p}}$ and $k_{\mathrm{t}}$ values for the iso-PMMA macromonomer than those for the syn-one indicate that the higher segmental mobility of iso-PMMA chain contributes to increase these kinetic parameters.

The ratio of $k_{\mathrm{p}}$ for the iso-macromonomer to that for $s y n$-macromonomers $(\sim 10)$ (see Table VI) is larger than the ratio of $\left(k_{11}\right)_{\text {iso }} /\left(k_{11}\right)_{\text {syn }}$ in the copolymerization with styrene as $\mathrm{M}_{2}$ monomer ( 2.5) (see eq 5). The smaller tacticity effect in the copolymerization may be ascribed to the lower density of PMMA segments around the propagating radicals due to the incorporation of styrene units. Thus, the monomer sequence distribution around the propagating radical may be an important factor to determine the rate of propagation, that is, the penultimate effect should be taken into consideration in the strict sense. Monomer reactivity ratio $r_{2}$, however, may be a good measure for the relative reactivity of macromonomer toward styrene radical. The ratio of reactivities of iso- and syn-PMMA macromonomers toward styrene radical could be estimated as 1.26 from $r_{2}$ values (see Table III). Therefore, the tacticity effect increased in the following order.

$$
\begin{array}{lllll} 
& k_{21} & <k_{11} & <k_{\mathrm{p}} & <k_{\mathrm{t}} \\
\text { iso-/syn- } & 1.26 & \sim 2.5 & \sim 10 & \sim 100
\end{array}
$$

The order is consistent with the increasing number of PMMA chains involved in each process, indicating that the mutual interaction between the PMMA chains plays an important role in determining the rate constant for propagation process.

The $v$ value for the polymerization of PMMA macromonomers at $60^{\circ} \mathrm{C}$ was calculated using the kinetic parameters obtained in this work and eq 2 . The $v$ values and the observed DP's of the polymacromonomer are listed in Table VI. In all the cases, the DP's are apparently smaller than the calculated ones, indicating the chain transfer reaction to occur. A number of initiator fragment in the polymacromonomer molecule, $N$, was found to be less than unity $(0.50-0.72)$ from the end group analysis. ${ }^{36}$ The result also confirms the occurrence of the chain transfer reaction. Thus, in the radical polymerization of macromonomers, high segmental density around the propagating radicals not only decreases the rates of elementary processes $\left(k_{\mathrm{t}}\right.$ and $k_{\mathrm{p}}$ ) but also changes the reaction pathway. The $N$ values for $s y n$ macromonomers $(0.50-0.65)$ were smaller than that for iso-macromonomer (0.72), indicating the higher frequency of the chain transfer reaction for the syn-macromonomer, probably because the termination reaction between polymacromonomer radicals is more strongly restricted for the syn-macromonomer than for the iso- one. Therefore, the stereo- 
regularity of PMMA macromonomer affects not only the rates of elementary processes but also the frequency of the transfer reaction.

Acknowledgments. The authors are grateful to Professor M. Kamachi of Osaka University for his helpful discussion. They thank Professor T. Kotaka and Dr. K. Adachi of Osaka University for the use of GPCLALLS equipments. They are also indebted to Mr. T. Iijima for his experimental support. A part of this work was financially supported by a Grant-in-Aid for Scientific Research (C) (No. 01550717) from the Ministry of Education, Science, and Culture of Japan, and by Kurata Foundation (1989-1990).

\section{REFERENCES}

1. R. Milkovich and M. T. Chiang, U.S. Patent, 3,786,116 (1974); R. Milkovich, Polym. Prepr., Polym. Chem. Div., Am. Chem. Soc., 21, 40 (1980).

2. P. F. Rempp and E. Franta, Adv. Polym. Sci., 58, 1 (1984).

3. Y. Yamashita, J. Appl. Polym. Sci., Appl. Polym. Symp., 36, 193 (1981).

4. R. Asami and M. Takaki, Makromol. Chem., Rapid Commun., 12, 163 (1985).

5. K. Ito, Kobunshi Kako (Polymer Applications), 35, 262 (1986).

6. Y. Tsukahara, K. Mizuno, S. Segawa, and Y. Yamashita, Polym. Prepr. Jpn., 37, 336 (1988); Macromolecules, 22, 1546 (1989).

7. K. Tanaka, K. Ito, and E. Yamada, Polym. Prepr. Jpn., 37, 337 (1989).

8. M. Takaki and R. Asami, Polym. Prepr. Jpn., 37, 335 (1988).

9. G. Schulz and R. Milkovich, J. Polym. Sci., 22, 1633 (1984).

10. P. Rempp, P. Lutz, P. Masson, and E. Franta, Makromol. Chem., Suppl., 13, 471 (1985).

11. J. P. Kennedy and M. Hiza, J. Polym. Sci., 21, 1033 (1983); J. P. Kennedy and C. Y. Lo, Polym. Bull., 13, 343 (1985).

12. K. Ito, H. Tsuchida, A. Hayashi, T. Kitano, W. Yamada and T. Matsumoto, Polym. J., 17, 827 (1985); K. Ito, H. Tsuchida, and T. Kitano, Polym.
Bull., 15, 425 (1986).

13. G. G. Cameron and M. S. Chisholm, Polymer, 26, 437 (1985).

14. K. Muehlbach and V. Percec, J. Polym. Sci., Polym. Chem., 25, 2605 (1987).

15. K. Ute and K. Hatada, Kobunshi Kako (Polymer Applications), 36, 366 (1986).

16. K. Hatada, H. Nakanishi, K. Ute, and T. Kitayama, Polym. J., 18, 581 (1986).

17. K. Hatada, T. Shinozaki, K. Ute, and T. Kitayama, Polym. Bull., 19, 231 (1988).

18. H. Yuki and K. Hatada, Adv. Polym. Sci., 31, 1 (1979).

19. K. Hatada, T. Kitayama, and K. Ute, Adv. Polym. Sci., 13, 189 (1988).

20. E. V. Thompson, J. Polym. Sci., A-2, 4, 199 (1966).

21. K. Hatada, T. Kitayama, Y. Okamoto, K. Ohta, Y. Umemura, and H. Yuki, Makromol. Chem., 179, 485 (1978).

22. K. Hatada, K. Ute, K. Tanaka, T. Kitayama, and Y. Okamoto, Polym. J., 17, 977 (1985).

23. K. Hatada, K. Ute, K. Tanaka, Y. Okamoto, and T. Kitayama, Polym. J., 18, 1037 (1986).

24. T. Kitayama, T. Shinozaki, E. Masuda, M. Yamamoto, and K. Hatada, Polym. Bull., 20, 505 (1988).

25. T. Kitayama, T. Shinozaki, T. Sakamoto, M. Yamamoto, and K. Hatada, Macromol. Chem., Suppl., 15, 167 (1989).

26. K. Hatada, T. Kitayama, K. Ute, E. Masuda, T. Shinozaki, and M. Yamamoto, Polym. Bull., 21, 165 (1989).

27. K. Hatada, T. Kitayama, E. Masuda, and M. Kamachi, Makromol. Chem., Rapid Commun., 11, 101 (1990).

28. V. Jaacks, Makromol. Chem., 161, 161 (1972).

29. J. P. Van Hook and A. V. Tobolsky, J. Am. Chem. Soc., 80, 779 (1958).

30. M. S. Matheson, E. E. Auer, E. B. Bevilacqua, and E. J. Hart, J. Am. Chem. Soc., 73, 1700 (1951).

31. K. Hatada, T. Kitayama, and E. Masuda, Polym. J., 17, 985 (1985).

32. M. Kamachi, Adv. Polym. Sci., 82, 207 (1987).

33. E. Masuda, T. Kitayama, K. Hatada, and M. Kamachi, Polym. J., to be submitted.

34. Y. Tsukahara, K. Tsutsumi, Y. Yamashita, and S. Shimada, Macromolecules, 22, 2869 (1989).

35. K. Hatada, T. Kitayama, E. Masuda, M. Yamamoto, and T. Shinozaki, Polym. Prepr.Jpn., 37, 1487 (1988).

36. T. Kitayama, S. Kishiro, E. Masuda, and K. Hatada, Polym. Bull, 25, 205 (1991).

37. J. C. Bevington, Trans. Faraday Soc., 51, 1392 (1955). 